\title{
Multiple interventions improve analgesic treatment of supracondylar fractures in a pediatric emergency department
}

\author{
Robert N Porter $\mathrm{MD}^{1}$, Roger E Chafe $\mathrm{PhD}^{1}$, Leigh A Newhook $\mathrm{MD}^{1}$, Kyle D Murnaghan $\mathrm{BA}^{2}$
}

RN Porter, RE Chafe, LA Newhook, KD Murnaghan. Multiple interventions improve analgesic treatment of supracondylar fractures in a pediatric emergency department. Pain Res Manag 2015;20(4):173-178.

BACKGROUND: Provision of appropriate and timely treatment for pain in the pediatric population has been challenging. Children with painful conditions commonly present to emergency departments (EDs), a setting in which it may be particularly difficult to consistently provide timely analgesic interventions.

OBJECTIVES: To measure the effectiveness of a set of interventions in improving the rate and timeliness of analgesic medication administration, as well as appropriate backslab immobilization (application of a moldable plaster or fiberglass splint), in a pediatric ED.

METHODS: Data regarding pain management were collected on a consecutive sample of cases of supracondylar fracture over a 13-month period. This followed the implementation of a formal triage pain assessment and treatment medical directive, supplemented with relevant education of nursing and house staff, and posters in the ED. These data were compared with data previously collected from a similar cohort of cases, which presented before the interventions.

RESULTS: Postintervention, the proportion of patients treated with an analgesic within 60 min of triage increased from $15 \%$ to $54 \%(P<0.001)$, and the median time to administration of an analgesic decreased from $72.5 \mathrm{~min}$ to $11 \mathrm{~min}(\mathrm{P}<0.001)$. Rates for backslab application before radiography were similar before and after the intervention $(29 \%$ and $33 \%$, respectively; $\mathrm{P}=0.646$ ).

CONCLUSIONS: A multifaceted approach to improving early analgesic interventions was associated with considerably improved rates of early analgesic treatments for supracondylar fracture; however, no improvement in early immobilization was observed.

Key Words: Analgesics; Emergency; Orthopedic

$\mathrm{T}$ he long-term effects of untreated pain in children are well documented (1-3). However, timely and appropriate management of acute pain in this population has been a challenge in many settings, including the emergency department (ED), with unacceptably low rates of treatment or late treatment documented at both general and pediatric EDs $(4,5)$. A recent review of analgesic interventions for a painful condition (acute supracondylar humerus fracture) demonstrated low rates of timely interventions for both backslab immobilization (application of a moldable plaster or fibreglass splint) and analgesic medication administration in the ED at the Janeway Children's Health and Rehabilitation Centre (St John's, Newfoundland and Labrador) (6).

The objective of the present study was to examine the impact of a group of low-cost interventions aimed at multiple providers in improving timely analgesic treatments to children presenting to the ED. The

\section{De multiples interventions améliorent le traitement analgésique des fractures supracondyliennes en salle d'urgence pédiatrique}

HISTORIQUE : Il est difficile de trouver un traitement adapté et rapide de la douleur pour la population pédiatrique. Les enfants ayant des problèmes de santé douloureux consultent souvent en salle d'urgence (SU), où il peut être particulièrement difficile de prodiguer systématiquement des interventions analgésiques rapides.

OBJECTIFS : Mesurer l'efficacité d'une série d'interventions pour améliorer le taux et la rapidité de l'administration d'analgésique, ainsi que l'immobilisation pertinente avec une attelle postérieure (attelle malléable de plâtre ou de fibre de verre) dans une SU pédiatrique.

MÉTHODOLOGIE : Les chercheurs ont colligé les données relatives à la gestion de la douleur auprès d'un échantillon de cas consécutifs de fractures supracondyliennes sur une période de 13 mois. Cette collecte suivait l'adoption d'un triage officiel d'évaluation de la douleur et de directives thérapeutiques médicales, complétée par la formation pertinente du personnel infirmier et du personnel interne et l'apposition d'affiches en SU. Les chercheurs ont comparé ces données avec celles déjà colligées auprès d'une cohorte similaire de cas qui avaient consulté avant les interventions. RÉSULTATS : Après l'intervention, la proportion de patients ayant reçu un traitement analgésique dans les 60 minutes suivant le triage est passée de $15 \%$ à $54 \%(\mathrm{P}<0,001)$, et la période médiane avant l'administration d'analgésique a reculé de 72,5 minutes à 11 minutes $(\mathrm{P}<0,001)$. Le taux d'installation d'attelles postérieures avant la radiographie était similaire avant et après l'intervention ( $29 \%$ et $33 \%$, respectivement; $\mathrm{P}=0,646$ ). CONCLUSIONS : Une démarche multidimensionnelle pour améliorer les interventions analgésiques précoces s'associait à un taux d'amélioration considérable du traitement analgésique précoce d'une fracture supracondylienne. Cependant, les chercheurs n'ont observé aucune amélioration de l'immobilisation précoce.

interventions included a medical directive mandating pain assessment and allowing triage nurses to treat mild to moderate pain without a physician's order, written educational material aimed at house staff rotating through the $\mathrm{ED}$, and educational posters.

\section{Study design}

\section{METHODS}

The present study prospectively examined pain management in a consecutive sample of cases of acute supracondylar fracture after a set of interventions aimed at improving analgesia treatment, and compared outcomes with those of a previously studied retrospective cohort of similar patients (the latter consisting of all eligible patients presenting from 2005 to 2009) (6). Supracondylar fracture was studied because it is known to be associated with moderate pain (even for undisplaced fractures) (7), and its pain management was well characterized at the

\footnotetext{
${ }^{1}$ Pediatrics; ${ }^{2}$ Faculty of Medicine, Memorial University of Newfoundland, St John's, Newfoundland and Labrador

Correspondence: Dr Robert N Porter, Room 412, Janeway Pediatric Research Unit, Janeway Hostel, 300 Prince Philip Drive, St John's,

Newfoundland and Labrador A1B 3V6. Telephone 709-777-4575, fax 709-777-2965, e-mail rporter@mun.ca
} 


\section{What's Wrong with this Picture?}

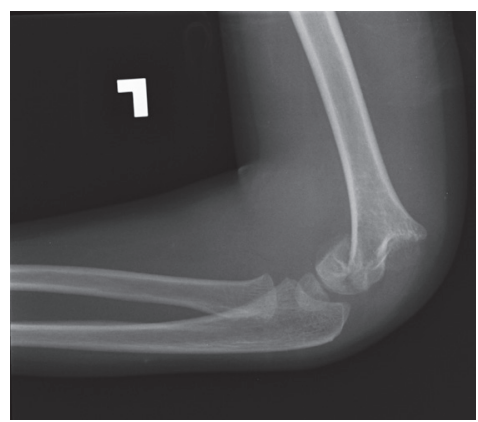

Don’t Forget: Immobilize Before You X-ray

Figure 1) Emergency department educational poster

institution studied. All patients presented to the ED of the Janeway Children's Health and Rehabilitation Centre (St John's, Newfoundland and Labrador), an academic ED and the only pediatric ED in Newfoundland and Labrador. This ED has an annual census of approximately 33,000 visits and is staffed by family physicians and pediatricians, with one pediatric emergency medicine fellowship-trained pediatrician on staff during portions of both time periods (before and after the intervention). Trainees included residents from multiple disciplines, including pediatrics (typically from four to seven residents per one-month rotation), as well as clinical clerks (typically two to four per two-week rotation). Triage is performed by a mixture of full-time and part-time triage nurses with some coverage by other experienced ED nurses, especially at night. Triage training was variable among nurses performing triage. Ethics and institutional approvals were obtained from the Newfoundland and Labrador Health Research Ethics Authority and Eastern Health, the Regional Health Authority with administrative responsibility for the Janeway ED.

\section{Selection of sample}

The sample included all eligible patients presenting to the ED between January 1, 2013 and January 31, 2014 (this was one month longer than planned due to a lower than expected number of cases). The inclusion criteria were: age zero to 12 years (to encompass the vast majority of supracondylar fractures while avoiding older children with more complex elbow injuries) (8); history of trauma within $24 \mathrm{~h}$ of triage; and radiograph positive for supracondylar humerus fracture. Effusion-only results on the initial radiograph were not eligible. Patients were excluded if they arrived with a backslab already in place, if they were initially seen by the orthopedic service (direct referrals) or if they were intubated due to major trauma. A diagnosis of supracondylar fracture was based on the written reports of radiologists experienced in interpreting pediatric radiographs.

The sample was obtained by reviewing all elbow radiographs ordered from the ED during the relevant time period using the picture archiving and communication system, and examining medical records to determine eligibility. The inclusion and exclusion criteria as well as the sample selection methodology were identical to those used for the preintervention comparator sample.

\section{Intervention}

Before collection of the prospective sample, interventions aimed at nurses and physicians were performed.

The nursing intervention consisted of a triage pain assessment and treatment medical directive developed by one of the authors (RP) and the ED nursing clinical educator. Approval was obtained from the Clinical Chief of Child Health on August 27, 2012, and the ED nurses were in-serviced on the new medical directive by means of didactic presentations by the ED nursing clinical educator during education days in September and October 2012. Nurses joining the ED after October 2012 were educated on the medical directive as part of their orientation; there were no refresher sessions. The directive mandated pain assessment and scoring for all patients presenting to the ED with painful conditions, and permitted (but did not require) the nurse to offer treatment for pain of mild to moderate intensity ( $\leq 7$ of 10 ) with ibuprofen or acetaminophen. Triage nurses could assign a pain score of 1 to 10 using a verbal-numerical scale or the Wong-Baker FACES ${ }^{\circledR}$ scale (Oklahoma City, USA). If the patient was judged to be too young or otherwise incapable of providing a self-report, pain was to be rated as mild, moderate or severe based on a general overall impression. In each case, the pain intensity was to be documented on the triage record. A copy of the directive is included as Appendix A.

Because backslab application was performed almost exclusively by staff physicians and trainees (occasionally by plaster technicians) in the ED studied, and because there were significant institutional barriers to the performance of this task by triage nurses (availability of space, significant investment in education), interventions to improve this aspect of care were aimed at medical professionals. For house staff, additional information was added to the orientation material distributed for review at the beginning of their pediatric emergency rotations. This emphasized that if a child with a suspected fracture presents with a visible deformity or severe pain, the extremity should be immobilized with a backslab and appropriate analgesia provided before the patient is sent to diagnostic imaging, with special mention of elbow injuries (the information was printed in bold as part of a four-page orientation handout). To encourage house staff and staff physicians to immobilize likely fractures before imaging, posters were created depicting a radiograph of a displaced supracondylar fracture with no backslab, with the caption, "What's Wrong with this Picture?" followed by, "Don't Forget: Immobilize Before you X-ray" (Figure 1). These were placed in the cast room and the main nursing station of the ED near the radiograph viewing area. Other than the posters, no specific education was aimed at staff physicians. A timeline of study-related activities is presented in Figure 2.

\section{Data collection}

A detailed review of the electronic medical chart was conducted and the following data extracted for each case: age (in months); sex; weight in kilograms; site of injury (left or right); Canadian Triage and Acuity Scale (CTAS) level; classification as severe or nonsevere; recorded pain score (initial nurse assessment); details of any analgesic administered before arrival at the ED; details of first analgesic medication administered in the ED, including time elapsed from triage; whether the first analgesic given in the ED preceded radiography; whether a backslab was applied before radiography; whether initial contact was with the emergency physician (EP) or a member of the house staff; and location of the child after triage (examination room, observation room or trauma room). Cases were classified as severe or nonsevere based on definitive treatment (as with the preintervention cohort, any case requiring either closed reduction or an operative procedure was classified as severe; all other cases were considered nonsevere). Other than pain scores, these data had been previously extracted from the preintervention data set (formal triage pain scoring was not part of patient assessment during the preintervention time period).

\section{Outcomes}

The primary outcome was the proportion of cases treated with an analgesic during the first $60 \mathrm{~min}$ of the $\mathrm{ED}$ visit. Secondary outcomes were the proportion of cases treated with an analgesic within $30 \mathrm{~min}$, median time to analgesic, proportion treated at any time, proportion treated before radiography, and proportion immobilized with a longarm backslab before radiography.

\section{Sample size}

All patients presenting within a one-year period were to be included in the sample. This was a convenience sample. It was anticipated that a minimum of 24 cases would be collected in this time period; in the 


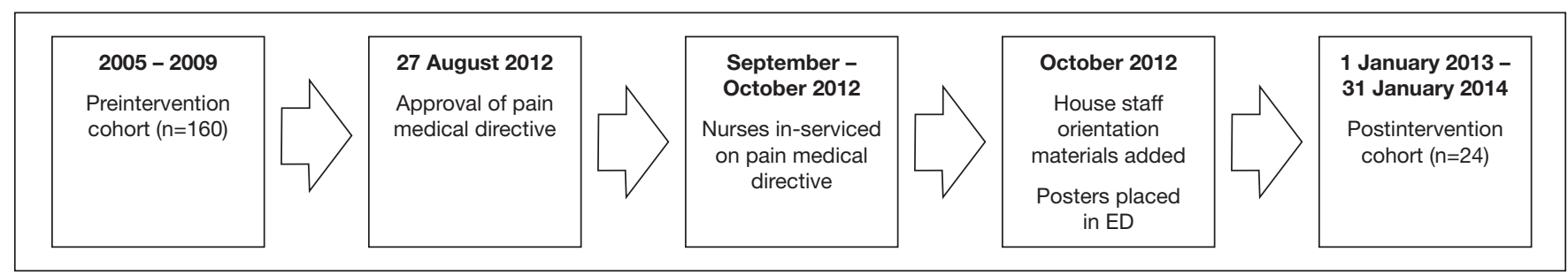

Figure 2) Timeline of study-related activities. ED Emergency department

TABLE 1

Baseline characteristics of post- and preintervention samples

\begin{tabular}{lccc}
\hline Characteristic & $\begin{array}{c}\text { Postintervention } \\
(\mathbf{n = 2 4 )}\end{array}$ & $\begin{array}{c}\text { Preintervention } \\
(\mathbf{n = 1 6 0 )}\end{array}$ & $\mathbf{P}$ \\
\hline Male sex & $8(33)$ & $93(58)$ & 0.023 \\
Age, months, mean \pm SD & $67.2 \pm 27.3$ & $70.4 \pm 29.2$ & 0.614 \\
Weight, kg, mean \pm SD & $22.6 \pm 8.9$ & $23.7 \pm 9.2(\mathrm{n}=153)$ & 0.594 \\
Fracture site left elbow & $16(67)$ & $93(58)$ & 0.427 \\
Initial medical contact EP & $15(62.5)$ & $71(44)$ & 0.097 \\
Location observation room & $4(17)$ & $25(16)$ & $>0.999^{*}$ \\
Prehospital analgesic & $5(21)$ & $7(4)$ & $0.011^{*}$ \\
Triage code & & & \\
2 & $8(33)$ & $8(5)$ & \\
3 & $14(58)$ & $127(79)$ & \\
4 & $2(8)$ & $25(16)$ & $<0.001$ \\
Severe injury & $6(25)$ & $44(27.5)$ & 0.797 \\
Time to medical contact, & $10(7.5-18.0)$ & $15(8.0-29.0)$ & $0.397^{\dagger}$ \\
min, median (IQR) & $(\mathrm{n}=21)$ & $(\mathrm{n}=99)$ & \\
\hline
\end{tabular}

Values are presented as $n(\%)$ unless otherwise indicated. $P$ values were calculated using $X^{2}$ unless otherwise indicated. *Fisher's exact test; ${ }^{\top}$ MannWhitney $U$ test. EP Emergency physician; IQR Interquartile range

event that $<24$ cases were collected in one year, it was planned to extend the time period.

\section{Statistical analysis}

Data were entered into an Access (Microsoft Corporation, USA) database and exported into SPSS version 20 (IBM Corporation, USA) along with an existing data set from the preintervention cohort (all cases from 2005 through 2009). A $\chi^{2}$ statistic or Fisher's exact test was used to compare categorical outcomes and a Student's $t$ test was used for continuous normal data. Medians were compared with a Mann-Whitney U test; $\mathrm{P}<0.05$ was considered to be statistically significant.

\section{RESULTS}

The baseline characteristics of the post- and preintervention samples are shown in Table 1. Of the 24 cases in the postintervention sample, fewer were male, more received a prehospital analgesic and acuity was judged to be higher based on CTAS codes than in the preintervention sample. More patients had initial contact with a staff EP rather than a member of the house staff in the postintervention sample; however, this was not statistically significant. There were four children in the postintervention group who were $<3$ years of age (for whom either of the self-report scales was likely not useful, but for whom a general impression of mild, moderate or severe pain was reported).

Table 2 summarizes outcomes from the study. After the interventions, the proportion of cases treated within 60 min of triage was $54 \%$ (13 of 24) versus $15 \%$ (24 of 160) in the preintervention cohort $(\mathrm{P}<0.001)$, with median times from triage to analgesic administration of $11 \mathrm{~min}$ (interquartile range $6.25 \mathrm{~min}$ to $50.00 \mathrm{~min}$ ) and $71.5 \mathrm{~min}$ (interquartile range $41.25 \mathrm{~min}$ to $140.25 \mathrm{~min}$ ), respectively $(\mathrm{P}<0.001)$. In the postintervention sample, $67 \%$ (16 of 24$)$ of patients received an
TABLE 2

Outcomes in post- and preintervention samples

\begin{tabular}{|c|c|c|c|}
\hline Outcome & $\begin{array}{l}\text { Postintervention } \\
\qquad(n=24)\end{array}$ & $\begin{array}{l}\text { Preintervention } \\
(n=160)\end{array}$ & $\mathbf{P}$ \\
\hline Analgesic $\leq 60 \mathrm{~min}$ & $13(54)$ & $24(15)$ & $<0.001^{*}$ \\
\hline Analgesic $\leq 30 \mathrm{~min}$ & $12(50)$ & $8(5)$ & $<0.001^{*}$ \\
\hline $\begin{array}{l}\text { Any analgesic during the } \\
\text { ED visit }\end{array}$ & $16(67)$ & $56(35)$ & 0.003 \\
\hline $\begin{array}{l}\text { Time to analgesic, min, } \\
\text { median (IQR) }\end{array}$ & $11(6.25-50.00)$ & $71.5(41.25-140.25)$ & $<0.001^{\dagger}$ \\
\hline Analgesic preradiography & $12(50)$ & $12(7.5)$ & $<0.001^{*}$ \\
\hline Backslab preradiography & $8(33)$ & $46(29)$ & 0.646 \\
\hline Pain score documented & $4(17)$ & $\mathrm{n} / \mathrm{a}$ & $\mathrm{n} / \mathrm{a}$ \\
\hline
\end{tabular}

Values are presented as $n$ (\%). $P$ values were calculated using $X^{2}$ unless otherwise indicated. *Fisher's exact test; ${ }^{\dagger}$ Mann-Whitney $U$ test. ED Emergency department; IQR Interquartile range; n/a Not applicable

analgesic at any time during the ED visit versus 35\% (56 of 160) in the preintervention sample $(\mathrm{P}=0.003)$.

Of the 16 patients treated with an analgesic during the ED visit, five received an analgesic medication in triage (before physician contact), of whom only one had a documented pain score, and 11 patients had a physician-ordered analgesic. Medications used were intranasal fentanyl (three cases), oral ibuprofen (10 cases) and subcutaneous morphine (three cases).

In the postintervention cohort, four patients had recorded triage pain scores (all coded on a scale ranging from 1 to 10). These four patients were treated with ibuprofen, one (rated 6 of 10) by the triage nurse according to the medical directive, and the other three by physician order. Of these three, two (rated 9 of 10 and 10 of 10) received the medication promptly (at $13 \mathrm{~min}$ and $11 \mathrm{~min}$ ) and one (rated 7 of 10) at $87 \mathrm{~min}$ (this patient received acetaminophen at home $40 \mathrm{~min}$ before triage). Of the eight patients who received no analgesic during their visit, three received a prehospital analgesic and two had a backslab applied before radiography.

Backslab application before radiography was similar in the postand preintervention cohorts (33\% [eight of 24] versus 29\% [46 of 160], respectively; $\mathrm{P}=0.646$ ). For severe injuries (those requiring closed reduction or an operative procedure), immobilization before radiography was performed in $50 \%$ (three of six) of cases after the intervention versus $61 \%$ ( 27 of 44$)$ before the intervention $(P=0.672)$.

\section{DISCUSSION}

Treatment of pain related to musculoskeletal injuries in children continues to be suboptimal. In a recent retrospective study of children with isolated long bone fractures requiring hospital admission, 59\% of children received no analgesia within the first hour of arrival and only $10 \%$ received an appropriately dosed analgesic within this time frame (9). In a review of a pediatric and a general ED in Alberta, most children with musculoskeletal injuries did not receive an analgesic during their visit; in children with fractures seen in the pediatric ED, only $39 \%$ received an analgesic (10).

A multifaceted structured intervention aimed at improving pain treatment in a pediatric ED has shown efficacy, although it was unclear 
which interventions were of most value (11). In an adult ED, a threecomponent intervention, including an expanded selection of analgesics, a standardized analgesia protocol and education sessions, increased the proportion of patients receiving an analgesic and the mean time to first analgesic (12). Protocols for nurse-initiated analgesia in particular have shown positive results for pediatric patients $(13,14)$, and have been identified by ED nurses to be an enabler for optimal pain management (15).

In the present study, the set of interventions was effective in improving early analgesic medication administration for cases of acute supracondylar fractures, although the pain directive was seldom followed strictly with respect to documentation of pain assessment. The discrepancy between documented pain scores and triage nurseinitiated treatment may be related to the lack of a dedicated placeholder on the triage sheets for the pain score. Modification of the triage sheet to encourage such documentation, chart audits with feedback and ongoing educational sessions may increase both pain assessment and its documentation.

Poor adherence to the pain directive may also be related to perceived weaknesses and impracticalities of the pain assessment process. Previously identified barriers to pain assessment and management by ED nurses include workload issues, a perceived reluctance of patients to report pain and a lack of confidence in the reliability of children's self-report of pain $(15,16)$. In the present study, the choice of different pain assessment methods was offered with the goal of maximizing uptake by offering options that individual triage nurses may be more comfortable with. Additional considerations were that the population included children who were too young for a self-report scale and that time pressure would likely be a factor in a busy ED. It may be that efforts to engage nurses more fully in the development and implementation of future policies for pain assessment may be of benefit in bridging the gap between policy and practice.

In spite of low rates of pain score documentation, pain treatment improved significantly, with nurse-initiated analgesic treatment playing a role. The relationship between pain scoring and analgesic treatment in the present study is interesting, although the small sample size limits definitive conclusions. For example, all patients for whom a pain score was documented received an analgesic, either in triage or by physician order. This may be due to an influence of the process of pain scoring on the outcome of analgesic treatment or, alternatively, nurses may have decided to score pain on those cases they perceived needed treatment. Conversely, of the five patients treated in triage, only one was scored. While some form of pain assessment would have been performed in these cases, which were treated according to the medical directive, no score was documented. Whether this assessment was simply an overall clinical impression or whether a more formal score was performed but not documented is unknown. Although a large retrospective study of pediatric ED visits in the United States showed an association between pain score documentation and analgesic treatment (17), efforts to improve pain management by improving pain scoring have not always been successful $(18,19)$.

It is likely that some analgesic doses ordered by physicians were indirectly influenced by the pain medical directive. For example, two patients had pain scores in the severe range, where independent treatment by nurses was outside of the scope of the medical directive. They received early analgesic by physician order, possibly as a consequence of the pain directive. Nurses seeking medical orders for analgesics outside the scope of a medical directive after the start of such a directive has been noted anecdotally in a previous study (14).

The higher-acuity CTAS levels assigned to cases in the postintervention sample may be related to more appropriate use of pain as a modifier in the triage process. Of note, the proportion of injuries classified as severe was similar. The fact that more cases in the postintervention group received a prehospital analgesic would favour decreased early analgesic administration in this group; however, it is possible that inquiry into and documentation of prehospital analgesic administration may be positively affected by the institution of the pain policy.
The nonsignificant trend toward more initial contact with an EP rather than a member of the house staff may be related to the increased levels of physician coverage coincidentally instituted in the time period between presentation of the pre- and postintervention cases.

Immobilization of painful or unstable fractures with a backslab is normally performed by staff physicians or house staff in the ED studied. It is interesting that the interventions aimed at improving this aspect of pain management (posters and orientation materials) were not effective, although they were focused on the specific condition being studied. This finding contrasts with the interventions concerning early analgesic medication administration, which were directed primarily at nurses (the only intervention aimed at staff physicians was the posters, and these dealt with immobilization only; the information for the house staff dealt with analgesia only to the extent that it should be provided with immobilization before radiography). This discrepancy may be related to the types of educational interventions (orientation materials and posters versus a medical directive and in-servicing) and interprofessional differences. Identified physician barriers to pain management in children include lack of time/disruption of flow, education, staffing, and difficulty identifying and quantifying pain (20).

\section{Strengths and limitations}

A strength of the present study was that consecutive samples of cases of a specific painful injury were examined in an identical fashion before and after the interventions, minimizing the effect of differences in the variety or severity of clinical presentations.

Some of the weaknesses of the present study include the inability to control other changes in ED practice over time (such as changes in staffing). We studied only a single condition and at a single centre, and some of the interventions were focused on the studied condition. The reasons for the choices not to backslab before radiography and not to treat with an analgesic were not explored in the present study. The small size of the postintervention sample was a limitation of the study; however, the methodology was such that all eligible patients who presented during the postintervention study period were included, and the sampling period covered more than a year, mitigating the effect of seasonal variation. The clustering of cases in the summer months (one-half of the cases in the postintervention sample presented in July and August) limits the ability to assess whether the effect of the intervention waned over time.

Weaknesses of the intervention itself include the one-time nature of the education of nurses, the passive rather than active education of physicians and the limited input from front-line staff in the development of the intervention. In addition, as noted in Appendix A, the medical directive contained an error (in one location, mild to moderate pain was erroneously designated as 1 to 6 of 10). This is unlikely to have significantly affected the results as the intended definition of 1 to 7 of 10 is used elsewhere in the document, was used in the teaching around the medical directive and is used by CTAS (with which the nurses were familiar). Future interventions could be improved by ongoing education for nurses on pain policies, auditing of adherence to policies, as well as engaging nurses and physicians on the amelioration of obstacles to both pain assessment and appropriate treatment of identified pain.

\section{CONCLUSION}

The present study demonstrates that institution of a pain medical directive leads to an improvement in timely analgesic treatment of supracondylar fractures in a pediatric ED, an effect likely to extend to other painful conditions. This component of the intervention, aimed at nurses, appeared to be an important driver of improved care in the present study, although the poor adherence to pain scoring and documentation as a first step in pain treatment is disappointing. These observations, coupled with the relationship between ED crowding and decreased timeliness and effectiveness of analgesic delivery (21), support further development and promotion of triage nurse-initiated interventions for analgesia, and exploration of the reasons for lack of full engagement in the pain assessment process by front-line staff. 
Such time-sensitive interventions may include backslab immobilization of painful or unstable fractures, as well as administration of opioids in cases of severe pain. The fact that a number of patients received neither administration of analgesia nor fracture immobilization before radiography speaks to the need for efforts to continue to improve analgesic treatment.

FUNDING: Funding for this study was provided by the Child Health Program, Eastern Health, St John's, Newfoundland and Labrador.

\section{REFERENCES}

1. Hermann C, Hohmeister J, Demirakca S, Zohsel K, Flor H. Long-term alteration of pain sensitivity in school-aged children with early pain experiences. Pain 2006;125:278-85.

2. Weisman SJ, Bernstein B, Schechter NL. Consequences of inadequate analgesia during painful procedures in children. Arch Pediatr Adolesc Med 1998;152:147-9.

3. Pate JT, Blount RL, Cohen LL, Smith AJ. Childhood medical experience and temperament as predictors of adult functioning in medical situations. Child Health Care 1996;25:281-98.

4. Brown JC, Klein EJ, Lewis CW, Johnston BD, Cummings P. Emergency department analgesia for fracture pain. Ann Emerg Med 2003;42:197-205

5. Kellogg KM, Fairbanks RJ, O'Connor AB, Davis CO, Shah MN. Association of pain score documentation and analgesic use in a pediatric emergency department. Pediatr Emerg Care 2012;28:1287-92.

6. Porter RN, Chafe R, Mugford G, Newhook L, Furey A. Poor access to timely pain reduction interventions for pediatric patients with supracondylar humerus fracture. Pediatr Emerg Care 2013;29:796-800.

7. Oakley E, Barnett P, Babl FE. Backslab versus nonbackslab for immobilization of undisplaced supracondylar fractures:

A randomized trial. Pediatr Emerg Care 2009;25:452-6.

8. Henrikson B. Supracondylar fracture of the humerus in children. A late review of end-results with special reference to the cause of deformity, disability and complications. Acta Chir Scand Suppl 1966;369:1-72.

9. Dong L, Donaldson A, Metzger R, Keenan H. Analgesic administration in the emergency department for children requiring hospitalization for long-bone fracture. Pediatr Emerg Care 2012;28:109-14.

10. Kircher J, Drendel AL, Newton AS, Dulai S, Vandermeer B, Ali S. Pediatric musculoskeletal pain in the emergency department: A medical record review of practice variation. CJEM 2014;16:449-57.

11. Corwin DJ, Kessler DO, Auerbach M, Liang A, Kristinsson G. An intervention to improve pain management in the pediatric emergency department. Pediatr Emerg Care 2012;28:524-8.

12. Yanuka M, Soffer D, Halpern P. An interventional study to improve the quality of analgesia in the emergency department. CJEM 2008;10:435-9.

13. Boyd RJ, Stuart P. The efficacy of structured assessment and analgesia provision in the paediatric emergency department. Emerg Med J 2005;22:30-2.

14. Taylor SE, Taylor DM, Jao K, Goh S, Ward M. Nurse-initiated analgesia pathway for paediatric patients in the emergency department: A clinical intervention trial. Emerg Med Australas 2013;25:316-23.

15. Pretorius A, Searle J, Marshall B. Barriers and enablers to emergency department nurses' management of patients' pain. Pain Manag Nurs 2015;16:372-9.

16. Van Hulle Vincent C. Nurses' knowledge, attitudes, and practices: Regarding children's pain. MCN Am J Matern Child Nurs 2005;30:177-83.

17. Drendel AL, Brousseau DC, Gorelick MH. Pain assessment for pediatric patients in the emergency department. Pediatrics 2006;117:1511-8.

18. Kaplan CP, Sison C, Platt SL. Does a pain scale improve pain assessment in the pediatric emergency department? Pediatr Emerg Care 2008;24:605-8.

19. Jadav MA, Lloyd G, McLauchlan C, Hayes C. Routine pain scoring does not improve analgesia provision for children in the emergency department. Emerg Med J 2009;26:695-7.

20. Ali S, Chambers A, Johnson DW, et al. Reported practice variation in pediatric pain management: A survey of Canadian pediatric emergency physicians. CJEM 2014;16:352-360.

21. Sills MR, Fairclough DL, Ranade D, Mitchell MS, Kahn MG. Emergency department crowding is associated with decreased quality of analgesia delivery for children with pain related to acute, isolated, long-bone fractures. Acad Emerg Med 2011;18:1330-8. 
APPENDIX 1

JANEWAY EMERGENCY CHILDREN'S AND WOMEN'S HEALTH PROGRAM • MEDICAL DIRECTIVE - PAIN MANAGEMENT PRESENTING SYMPTOM Pain:

OR COMPLAINT • Mild to moderate pain (pain scale 1-7/10)

- Examples include: minor sprains, minor burns, toothache, non-displaced fracture and otitis media.

AUTHORIZATION TO INITIATE Registered Nurses who work in the Janeway Emergency Department

EDUCATION PROCESS Completion of education on Medical Directives

RANGE OF CLIENTS

EXCLUSION CRITERIA

Children between 3 months and 18 years with mild to moderate pain

Patients:

- Less than 3 months of age

- With abdominal pain

lbuprofen contraindications:

- Capillary refill greater than 2 seconds or appearance of dehydration

- Within 14 days post-op tonsillectomy/adenoidectomy

- Any post-op patients that have been advised by their physician to avoid ibuprofen / non-steroidal anti-inflammatory drugs (NSAIDS)

- Oncology patients

- Bleeding disorders

- History of gastrointestinal or kidney disease

- Allergy to ibuprofen or other NSAIDS

Acetaminophen contraindications:

- Allergy to acetaminophen

\begin{tabular}{l}
\hline CONSENT \\
\hline PROCEDURE \\
- Assessment \\
- Implementation \\
- Evaluation/ Reassessment/ \\
Monitoring \\
- Documentation
\end{tabular}
No special consent is required

Assessment

- Vital signs (including capillary refill, weight in $\mathrm{kg}$ and pain severity assessment )

- Allergies

- Medications (including any pain medication given-dose and time)

- Past and present medical conditions

Implementation

RN may initiate one dose of ibuprofen or acetaminophen:

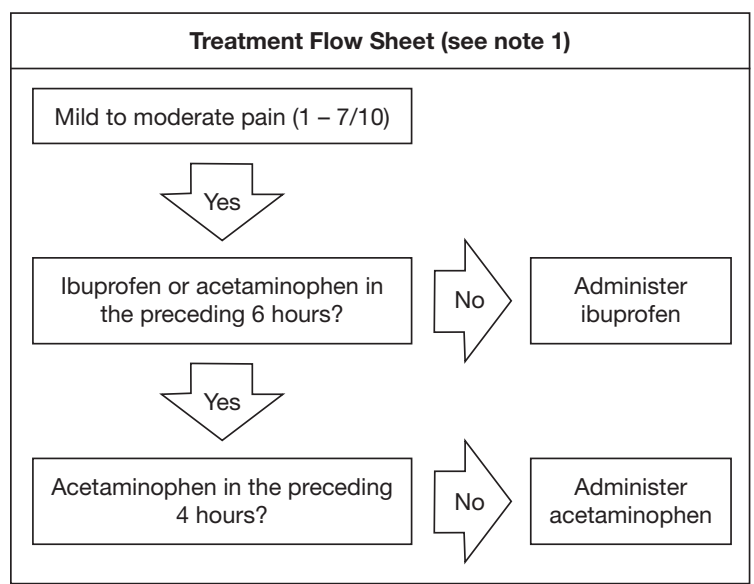

\begin{tabular}{|l|}
\hline \multicolumn{1}{|c|}{ Medications } \\
\hline Single one time dose: \\
$\underline{\text { lbuprofen }}$ \\
$5 \mathrm{mg} / \mathrm{kg}$ po (weight up to $10 \mathrm{~kg}$ ) \\
$10 \mathrm{mg} / \mathrm{kg}$ po (weight $10 \mathrm{~kg}$ or more) \\
Maximum dose of $600 \mathrm{mg}$ \\
Acetaminophen \\
$15 \mathrm{mg} / \mathrm{kg}$ po or rectally \\
Maximum dose of $1000 \mathrm{mg}$ \\
\hline
\end{tabular}

Note:

- Form of medication should be based on developmental stage and preference of child/caregiver. The oral route should not be used if child is unable to tolerate oral fluids.

- Children who are immune suppressed should never receive any medication by the rectal route unless specifically ordered by a physician. Rectal insertion may damage the mucous membrane and may increase the risk of infection due to entry of organisms through the damaged mucous membrane.

Evaluation/Reassessment/Monitoring

- As per Canadian Triage and Acuity Scale (CTAS)

- Reassessment of patients at 30 minutes post analgesic administration if patient not discharged (including Pediatric Assessment

Triangle and pain assessment).

Documentation

- Document on Janeway Emergency Department Record that medical directive is implemented

- Document assessment findings

- Document medications (including dose, route and time of administration)

- Document other procedures/interventions

- Document post administration assessment

AUTHORIZATION Clinical Chief, Child Health

DATE August 27th, 2012

REFERENCES 2008 Canadian Triage and Acuity Scale (CTAS)

The designation "1-7/10" in this table is corrected from the erroneous "1-6/10". See Discussion 


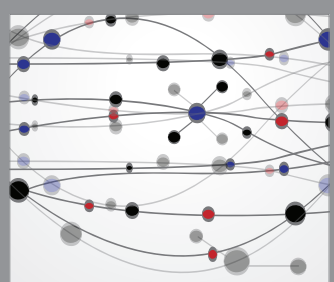

The Scientific World Journal
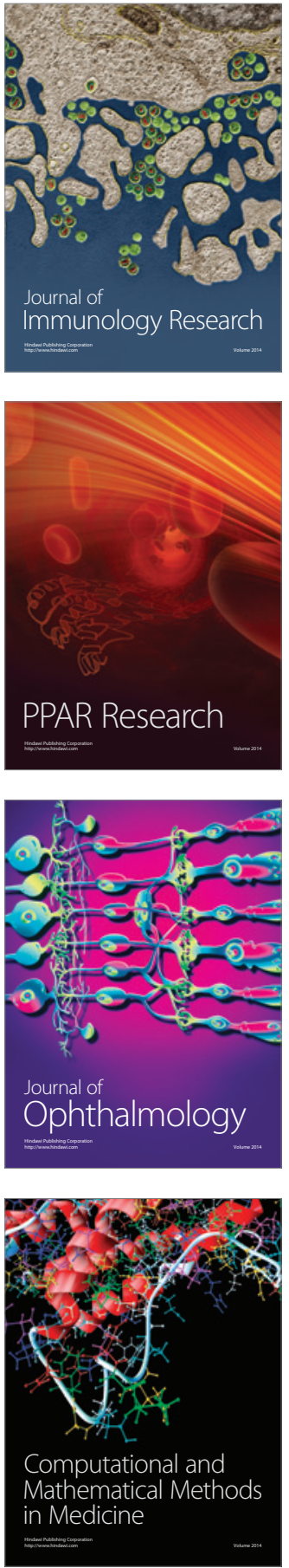

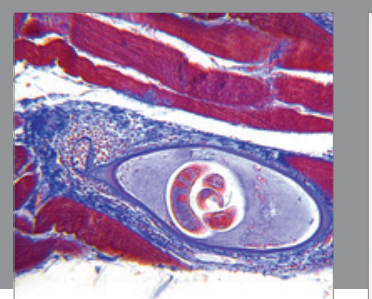

Gastroenterology Research and Practice

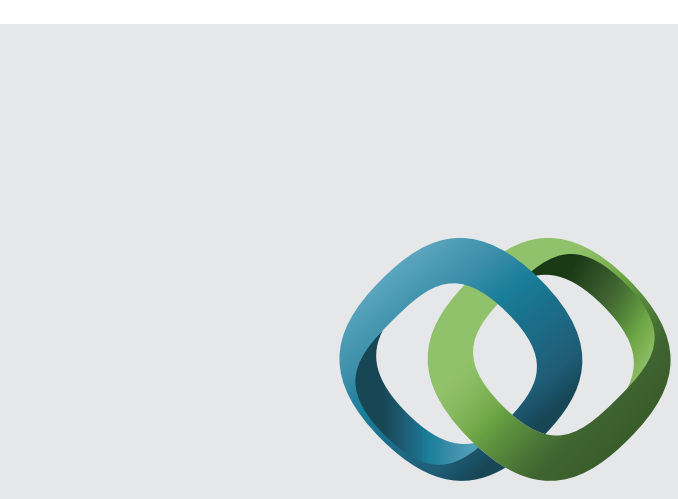

\section{Hindawi}

Submit your manuscripts at

http://www.hindawi.com
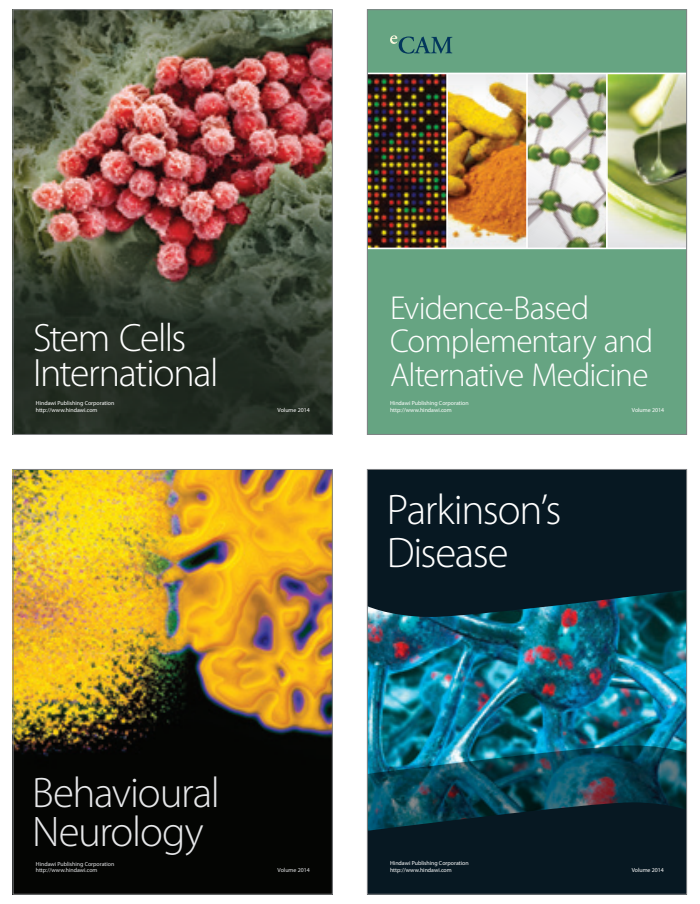
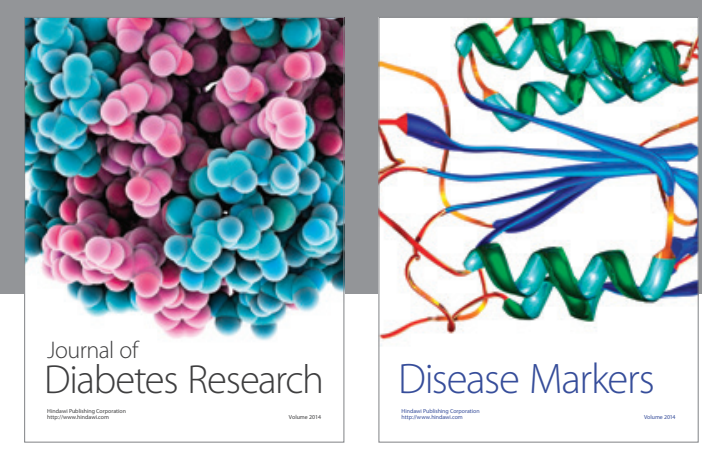

Disease Markers
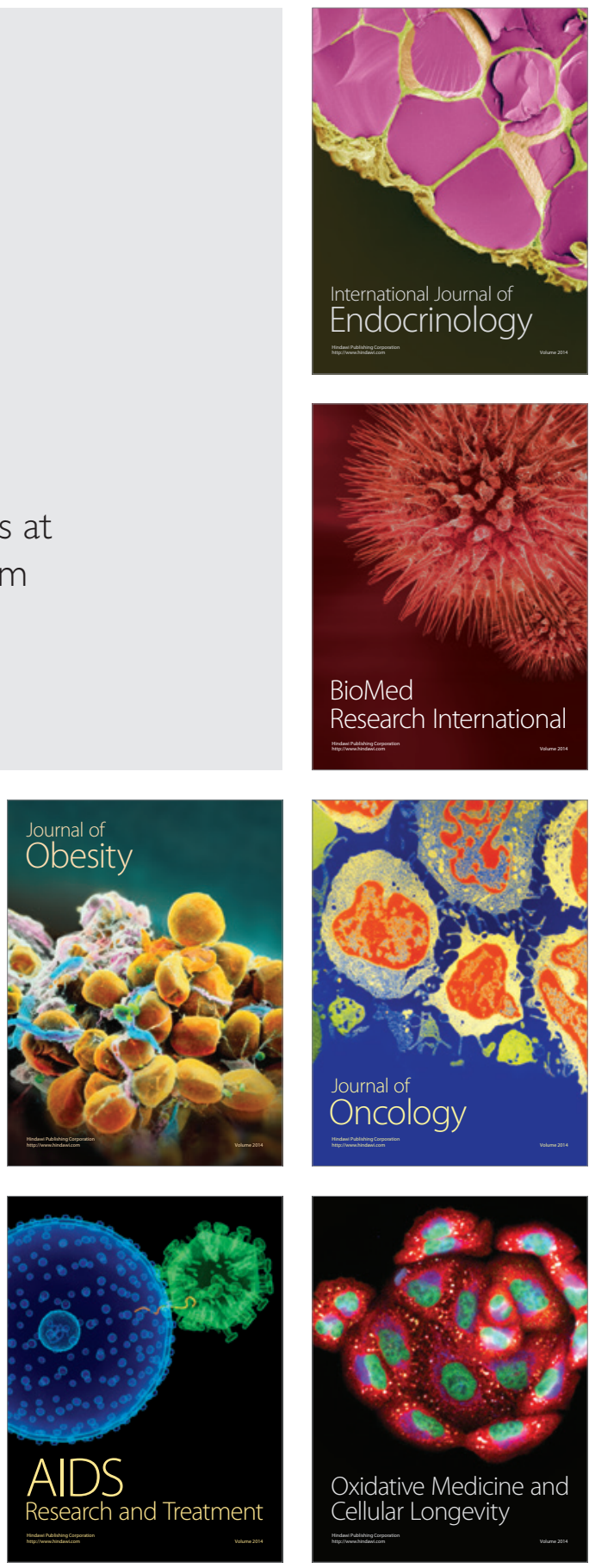